\title{
Energy Internet Evaluation Index System under the Zero Carbon Goal
}

\author{
Rui LI ${ }^{1}$ \\ ${ }^{1}$ State Grid Energy Research Institute Co., Ltd, Beijing, 102209, China
}

\begin{abstract}
At present, the zero-carbon goal has become the common choice of all the world. Driven by the zero-carbon goal, energy system in China will develop to be cleaner and cleaner. In this situation, Energy Internet has become the future development trend of the energy system. Based on the detailed analysis on the development history, the basic connotation and the key features of Energy Internet, an Energy Internet evaluation index system is introduced. This proposed indicator system evaluates Energy Internet from five dimensions, and all the indexes include the qualitative and the quantitative indicators, the process indicators and the result indicators, the technical indicators and the economic indicators. On this basis, an evaluation method is proposed based on the Analytic Hierarchy Process and the Delphi method. The proposed evaluation index system and the evaluation method can provide a good objective evaluation of the development of Energy Internet.
\end{abstract}

\section{Introduction}

Energy is an important foundation for economic and social development. Since the reform and opening up, China's energy industry has developed rapidly and has become the world's largest energy producer and consumer, which strongly supports economic and social development. However, China's energy system has long been dominated by coal, and China is the world's largest carbon emitter. Therefore, the need for a clean and lowcarbon transition is urgent. On December 12, 2020, China announced that it would achieve a peak in carbon emissions in 2030 and zero carbon in 2060. Compared with the opinions expressed in the general debate of the 75th United Nations General Assembly, this goal emphasizes a series of new measures of national independent contributions, and provides time requirements and mission requirements for China to achieve the zero-carbon goal.

In order to accelerate the achievement of carbon emission peaks and zero-carbon goals, it is necessary to accelerate the development of the energy system to be cleaner, lower carbon, more efficient, and smarter. The power grid is a hub and bridge connecting power generation and electricity consumption, and an important link in promoting the transformation and upgrading of the energy system. Therefore, the power grid in China needs to be upgraded to Energy Internet. Considering its important position in the energy transition, the concept of Energy Internet has received extensive attention from research institutions, experts and scholars at home and abroad since it was put forward.

Based on the concept of the Internet, the basic architecture of Energy Internet is introduced in [1], by analyzing the three important characteristics, including the plug-and-play of distributed power sources, energy routers, and distributed intelligent management systems. Its emphasis on openness and interaction, which has been recognized by many other scholars. In [2], Energy Internet is a multi-energy complementary energy ecosystem, and the smart grid is considered as the main carrier of Energy Internet. The coordinated and complementary operation of multiple energy sources is the main point of this article. In [3], in order to achieve $100 \%$ renewable energy supply, a smart energy network that integrates power grids, natural gas networks, thermal systems, and transportation systems is proposed. In [4-5], several smart grid evaluation index systems have been developed, considering economy, energy, environment, society and engineering. These papers provide important references for the Energy Internet evaluation index system in this article.

On the basis of summarizing and sorting out the relevant theories and development history of Energy Internet, the basic connotation of Energy Internet is proposed. At the same time, following the combination of qualitative indicators and quantitative indicators, as well as the combination of process indicators and result indicators, the evaluation indicator system and evaluation methods of Energy Internet are proposed in this paper.

\section{The basic concept and connotation of Energy Internet}

\subsection{The development history of Energy Internet}

Corresponding author: lirui@sgeri.sgcc.com.cn 
The concept of Energy Internet appeared in 1970 and has a history of nearly 50 years. In general, the development of Energy Internet has gone through three stages, including concept budding (1970 to 2003), extensive exploration (2004 to September 2015), and intensified implementation (2015 and after).

The first stage: In the 1970s, Richard Buckminster Fuller proposed the concept of a world power network, which became the prototype of the concept of Energy Internet. In 1986, Peter Meisen founded the Global Energy Network Institute (GENI), aiming to make full use of the world's abundant renewable energy through power transmission lines between countries.

The second stage: In 2004, "The Economist" published "Building the Energy Internet" after the $8 \bullet 14$ power outage in the United States and Canada, and for the first time clearly advocated the construction of "Energy Internet". This article proposes that it is necessary to learn from the Internet's self-healing and plug-and-play features and technologies to build an intelligent, automated, and self-healing energy grid (Energy Internet), and transform the traditional power grid into a smart, responsive and self-healing digital network. Since then, the concept of Energy Internet has become more diversified.

\subsection{The basic connotation of Energy Internet}

Combined with long-term research and exploration, researchers have reached a great consensus on the concept of Energy Internet. It can be basically considered that Energy Internet is an integrated energy management and control system. The power system is its core and link. Wind energy, solar energy and other new energy sources and natural gas are its main primary energy sources. Large-scale, multi-form, distributed power and energy storage systems are widely connected. The new generation of communication technologies such as cloud computing, big data, and artificial intelligence are the energy utilization and management methods of Energy Internet. At the same time, multiple systems such as power systems, transportation systems, natural gas systems, and information communication systems are highly integrated. The purpose of Energy Internet is to realize the coordination and complementation of multiple energy sources, the coordinated interaction of source-grid-load-storage, and the realization of "clean replacement" and "electricity replacement" of the entire energy system.

\subsection{Basic characteristics of Energy Internet}

\subsubsection{Coordinate and complement among multiple energy sources}

Energy Internet is widely equipped with wind energy, solar energy, and other energy power generations. According to the operating characteristics of different energy sources, as well as the complementary characteristics of temporal and spatial distribution of them, Energy Internet scientifically configures various energy sources to achieve green development while ensuring the safety and stability of energy supply [2].

\subsubsection{Collaborative interaction among generations, grids, loads, and storages}

Based on energy routers and intelligent energy management systems, Energy Internet can actively manage distributed power sources and flexible loads. At the same time, relying on the coordination of multiple types and forms of energy storage, Energy Internet can realize the synergistic interaction among sources, grids, loads, and storages, thereby realizing the coordination and optimization of energy demand and production supply.

\subsubsection{High integration of multiple systems including power systems, gas systems, and heating systems}

Power system is the core and hub of Energy Internet. Power system integrates with transportation system by the grid-connected technology of electric vehicles; Power system integrates with the natural gas system by technologies such as natural gas power generation and electricity-to-gas technology; Power system integrates with heating system through the by technologies of combined supply of cooling, heating and power. The various physical devices involved in the power systems, natural gas systems, and transportation systems in Energy Internet integrate with the information communication system by energy routers to achieve the integration of energy flow and information flow.

\subsubsection{Wide-area interconnection of massive distributed equipment}

In Energy Internet, distributed devices such as wide-area and massive distributed power sources, energy storage devices, and flexible loads, are deeply interconnected. On this basis, through the opening of the energy market, Energy Internet can realize end-to-end diversified energy sharing, thereby improving the degree of refinement of demand-side resource management and the level of economic operation of the energy system.

\section{Development of Energy Internet evaluation index system}

\subsection{Significance}

First of all, Energy Internet evaluation index system is an important basis for measuring the development level of Energy Internet in China. At present, there are no specific standards to evaluate the development of Energy Internet for the zero-carbon goal. At the same time, because of the differences in the power grid, resource environment, and market mechanism between various countries, the relevant foreign standards have little reference value. Therefore, it is necessary to development an Energy Internet evaluation index system 
based on the actual situation of China, including power grid development, resource environment, and the mission requirements and time requirements for zerocarbon target, to provide evaluation benchmarks for evaluating Energy Internet in China.

Secondly, Energy Internet evaluation index system can provide important direction guidance for future development. Energy Internet evaluation index system is developed from multiple perspectives, which can provide the target guidance for the development of Energy Internet, and in the meanwhile, provide the guidance information and related suggestions for the planning and development of Energy Internet.

\subsection{Basic principles}

Firstly, the development of the provided evaluation index system requires a combination of qualitative and quantitative indicators. The analysis of existing measurable and measurable quantitative indicators can provide a detailed display of the development of Energy Internet. At the same time, qualitative analysis is also needed to describe objective. In addition, the evaluation index system also needs to qualitatively summarize and improve the results of quantitative analysis.

Secondly, Energy Internet evaluation index system requires a combination of process indicators and result indicators. Energy Internet evaluation index system needs to focus on the results and effectiveness of Energy Internet, as well as the process and key elements of the operation of Energy Internet.

Thirdly, Energy Internet evaluation index system requires a combination of technological innovation and value creation. Energy Internet evaluation index system not only reflects the advanced level of the overall technology of Energy Internet, but also needs to emphasize the value creation ability of Energy Internet, both of which are indispensable.

Fourthly, Energy Internet evaluation index system needs a combination of practicability and innovation. As Energy Internet has both practical and innovative orientations, Energy Internet evaluation index system needs to provide the evaluation and the analysis indicators from the perspective of objective and practical applications, and at the same time, it also needs to evaluate and analyze Energy Internet indicators from aspects such as technological innovation and system innovation.

Fifthly, Energy Internet evaluation index system requires a combination of individual indexes and common indexes. The evaluation index system of Energy Internet not only needs to fully consider the common characteristics and goals of Energy Internet, but also needs to comprehensively consider the grid structure and energy resource foundation of different Energy Internet.

\subsection{Development of the evaluation index system}

Based on an in-depth analysis of the development trend of Energy Internet, it is necessary to evaluate Energy Internet from five dimensions, including the clean energy supply, the electrification of energy consumption, the efficient energy use, the smart energy allocation, and the diversified energy services. In this paper, the indicators, which used to represent the clean energy supply, mainly include the proportion of clean energy electricity, the capacity proportion of clean energy power generation, the utilization rate of renewable energy power generation, the proportion of coal power. The indicators, which used to represent the electrification of energy consumption mainly includes indicators such as the proportion of electric energy in the final energy consumption, the reliability rate of power supply, and the comprehensive voltage qualification rate. The indicators, which used to represent the energy utilization efficiency mainly include the indicators such as the level of energy consumption per unit of GDP, coal consumption for power generation, and the rate of transmission losses. The indicators, which used to represent intelligent energy allocation mainly include the smart level of power grids, the digital development index, and the source-network-load-storage collaborative service index. The indicators, which used to represent diversified energy services the indicators such as the total revenue of comprehensive energy service business, electric vehicle service capabilities, the proportion of adjustable load resources, and customer service satisfaction.

\subsection{The design of evaluation method}

The method of combining analytic hierarchy process and Delphi method is adopted to set the weight of each dimension. The analytic hierarchy process is mainly divided into the following several steps. The first one is to arrange the various factors into several levels according to the affiliation. Then, to establish the comparison relationship between the elements of the two adjacent layers. On this basis, the importance of each index can be obtained, and the order of the indexes according to the importance can be obtained. The advantage of Analytic Hierarchy Process is that it embodies the characteristics of decomposition, judgment, and synthesis of human thinking, so the method has a better system and simple calculation. At the same time, the Delphi method used in this paper mainly uses the experience of multiple experts to determine the weight of each indicator. On this basis, multiple rounds of feedback are given to experts and the weights can be revised. The advantage of the Delphi method is that the opinions obtained are more concentrated and reliable.

The above process is specifically as follows. Based on the analytic hierarchy process, the judgment matrix is established, and the Delphi method is introduced in the process of forming the judgment matrix. This method can avoid the subjective guidance of individual experts and obtain more stable and objective results. Then based on the consideration of expert experience, the ranking of the importance of factors is formed. Finally, calculate the weights and check the consistency. 
Based on the method provided in this paper, the proposed Energy Internet evaluation index system is

given as follows.

Table 1. Energy Internet evaluation index system.

\begin{tabular}{|c|c|c|c|}
\hline Dimension & Grid category & Index & Weight \\
\hline \multirow{6}{*}{$\begin{array}{l}\text { Clean energy } \\
\text { supply }\end{array}$} & \multirow{6}{*}{$\begin{array}{l}\text { Receiving-end grid } \\
\qquad(24 \%) / \\
\text { Sending-end grid } \\
(16 \%)\end{array}$} & The proportion of clean energy electricity & $6 \% / 4 \%$ \\
\hline & & $\begin{array}{l}\text { Clean energy power delivered from outside the } \\
\text { district }\end{array}$ & $6 \% / 4 \%$ \\
\hline & & $\begin{array}{l}\text { Proportion of clean energy power generation } \\
\text { capacity }\end{array}$ & $4 \% / 2 \%$ \\
\hline & & $\begin{array}{l}\text { Renewable energy power generation utilization } \\
\text { rate }\end{array}$ & $4 \% / 2 \%$ \\
\hline & & $\begin{array}{c}\text { Proportion of coal in primary energy } \\
\text { consumption }\end{array}$ & $2 \% / 2 \%$ \\
\hline & & $\begin{array}{l}\text { Electricity coal accounts for the proportion of } \\
\text { coal consumption }\end{array}$ & $2 \% / 2 \%$ \\
\hline \multirow{4}{*}{$\begin{array}{l}\text { Electrification } \\
\text { of energy } \\
\text { consumption }\end{array}$} & \multirow{4}{*}{$\begin{array}{l}\text { Receiving-end grid } \\
\qquad(16 \%) / \\
\text { Sending-end grid } \\
(24 \%)\end{array}$} & $\begin{array}{l}\text { Electricity accounts for the proportion of final } \\
\text { energy consumption }\end{array}$ & $4 \% / 6 \%$ \\
\hline & & Alternative power & $4 \% / 6 \%$ \\
\hline & & Power supply reliability rate & $4 \% / 6 \%$ \\
\hline & & Comprehensive voltage qualification rate & $4 \% / 6 \%$ \\
\hline \multirow{4}{*}{$\begin{array}{l}\text { Energy } \\
\text { utilization } \\
\text { efficiency }\end{array}$} & \multirow{4}{*}{$\begin{array}{l}\text { Receiving-end grid } \\
\qquad(20 \%) / \\
\text { Sending-end grid } \\
(20 \%)\end{array}$} & Energy consumption per unit GDP & $4 \%$ \\
\hline & & Coal consumption for power generation & $4 \%$ \\
\hline & & Comprehensive line loss rate & $6 \%$ \\
\hline & & GDP terminal consumption & $6 \%$ \\
\hline \multirow{4}{*}{$\begin{array}{l}\text { Intelligent } \\
\text { energy } \\
\text { allocation }\end{array}$} & \multirow{4}{*}{$\begin{array}{l}\text { Receiving-end grid } \\
\qquad(24 \%) / \\
\text { Sending-end grid } \\
(16 \%)\end{array}$} & Intelligent level of energy allocation & $6 \% / 4 \%$ \\
\hline & & Grid intelligence level & $6 \% / 4 \%$ \\
\hline & & Digital Development Index & $6 \% / 4 \%$ \\
\hline & & $\begin{array}{l}\text { Source-network-load-storage collaborative } \\
\text { service index }\end{array}$ & $6 \% / 4 \%$ \\
\hline \multirow{5}{*}{$\begin{array}{l}\text { Diversified } \\
\text { energy } \\
\text { services }\end{array}$} & \multirow{5}{*}{$\begin{array}{l}\text { Receiving-end grid } \\
\qquad(16 \%) / \\
\text { Sending-end grid } \\
(24 \%)\end{array}$} & Business Environment Improvement Index & $4 \% / 6 \%$ \\
\hline & & Revenue from integrated energy service business & $4 \% / 6 \%$ \\
\hline & & Electric vehicle service capabilities & $4 \% / 4 \%$ \\
\hline & & Adjustable load resource ratio & $2 \% / 4 \%$ \\
\hline & & Customer service satisfaction & $2 \% / 4 \%$ \\
\hline
\end{tabular}

\section{Conclusion}

The development history, basic connotation, basic characteristics, and other aspects of Energy Internet are comprehensively analyzed in this paper. At the same time, a comprehensive evaluation index system for evaluating Energy Internet is developed. The proposed index system evaluates Energy Internet from five dimensions, and has strong operability. On this basis, the comprehensive evaluation method of Energy Internet is given in this paper, the scoring results obtained by the provided model and method can more reflect the stage of Energy Internet objectively.

\section{Acknowledgments}

The project is funded by SGCC Science and Technology Project "Research on Key Decision Supporting Technologies for Provincial Power Grid Companies to Build Energy Internet Enterprises 1300-201918281-A-00-00".

\section{References}

1. Huang, A. Q., Crow, M. L., Heydt, G. T. (2014) The future renewable electric energy delivery and management (FREEDM) system: the energy internet. Proceedings of the IEEE, 99(1): 133-148.

2. Dong, Z. Y., Zhao, J. H., Wen F. S. (2014) From smart grid to energy internet basic concept and 
research framework. Automation of Electric Power Systems, 38(15): 1-11.

3. Mathiesen, B. V., Lund. H., Connolly, D. (2015) Smart energy systems for coherent $100 \%$ renewable energy and transport solutions. Applied Energy, 145:139-154.

4. Jiang, L., Yuan, Y., Wang Z. (2016) Evaluation index system and comprehensive evaluation method of energy internet in innovative demonstration area of smart grid. Proceedings of the CSU-EPSA, 28(1): $39-45$.

5. Li, Y., Sun, Z. D., Han, L. (2017). Fuzzy comprehensive evaluation method for energy management systems based on an internet of things. IEEE Journals \& Magazines, 21312-21322. 